\title{
Jóvenes españoles migrantes en Chile: entre el crecimiento profesional y la ausencia de bienestar social $^{1}$
}

\author{
RubÉn RodRÍGUEZ-PUERTAS ${ }^{2}$ \\ Recibido: 01/04/2019 | Aceptado: 07/11/2019
}

\section{Resumen}

El presente trabajo, fundamentado en una investigación realizada en Chile entre los meses de marzo y junio de 2016, por un lado, y mediante las estadísticas proporcionadas por el Departamento de Extranjería y Migración, estudia las características sociodemográficas y los perfiles de aquellos ciudadanos españoles, que obtuvieron la visa de residencia durante el periodo 20102015. Y por otro lado, con la intención de comprender cómo son los procesos migratorios y la inserción sociocultural de estos migrantes, analiza, siguiendo los procedimientos de la Grounded Theory, los discursos obtenidos a través de once entrevistas en profundidad y un grupo de discusión, realizados a españoles residentes en Chile, con una edad comprendida entre los $25 \mathrm{y}$ 35 años, con titulación universitaria, y que llegaron al país entre 2010 y 2015. A través de dichos análisis, se muestra cómo esta emigración española se compone principalmente por jóvenes cualificados en profesiones técnicas como la ingeniería, la arquitectura o la geología. E igualmente, se pone de manifiesto la manera en que estos migrantes autodenominados "exiliados laborales", parecen seguir una inserción sociocultural en la sociedad chilena, que podríamos definir como nostálgica y que se caracteriza, principalmente, por la idealización del contexto de partida y del retorno.

Palabras clave: emigración española; jóvenes migrantes; migración cualificada; procesos migratorios, movilidad laboral

\begin{abstract}
Young Spanish migrants in Chile: between professional growth and a lack of social welfare

The present paper, based on a research carried out in Chile between March and June 2016, on the one hand studies the sociodemographic characteristics and the profiles of those Spanish citizens who obtained their resident visa during the period 20102015 and, on the other hand, tries to understand the migration processes and the sociocultural insertion of those migrants. The first goal is achieved by analyzing the statistics provided by the Chilean Department of alien status and migration. The second one has been carried out following the procedures of the Grounded Theory to analyze the discourses obtained through a discussion group and eleven in depth interviews with Spanish residents in Chile. The age of the participants was between 25 and 35 years,

1. Esta investigación forma parte del trabajo de campo realizado en Santiago de Chile y desarrollado en la Universidad Alberto Hurtado, entre los meses de marzo y junio de 2016, gracias a la financiación otorgada por la beca de movilidad internacional: Universidad de Granada y CEI BioTic Granada.

2. Universidad de Almería. rubenrp@ual.es
\end{abstract}


they had an university degree, and arrived in the country between 2010 and 2015. Through these analyses, the research shows how Spanish migration is composed mainly of young people qualified in technical professions like engineering, architecture or geology. Likewise, the way in which these migrants -self styled 'labor exiles'- seem to follow a socio cultural insertion in Chilean society that we could define as nostalgic and which is characterized, mainly, by the idealization of the context of departure and return, becomes evident.

Keywords: Spanish emigration; young migrants; qualified migration; migration processes; labour mobility.

\section{Introducción}

La fuerte crisis económica de alcance global que surgió en el ámbito de las finanzas a partir del año 2008, ha deteriorado varios ámbitos de la realidad social de los jóvenes españoles (principalmente el entorno laboral), agravando aún más sus ya debilitadas situaciones y empujándoles a un escenario de desempleo y precariedad crónicos. Este deterioro en las condiciones sociales y de calidad de vida de los jóvenes, ha generado importantes transformaciones en sus pautas sociales, destacando la aparición de un discurso migratorio que afecta principalmente a aquellos que tienen un mayor nivel de formación. Esta conducta se viene reflejando en el fuerte incremento de la emigración juvenil española (de 25 a 34 años de edad), que llegó a alcanzar cifras significativas durante el periodo 2010-2015 (véase figura 1).

Figura 1. Emigración juvenil española (25-34 años) durante el periodo 2005-2017

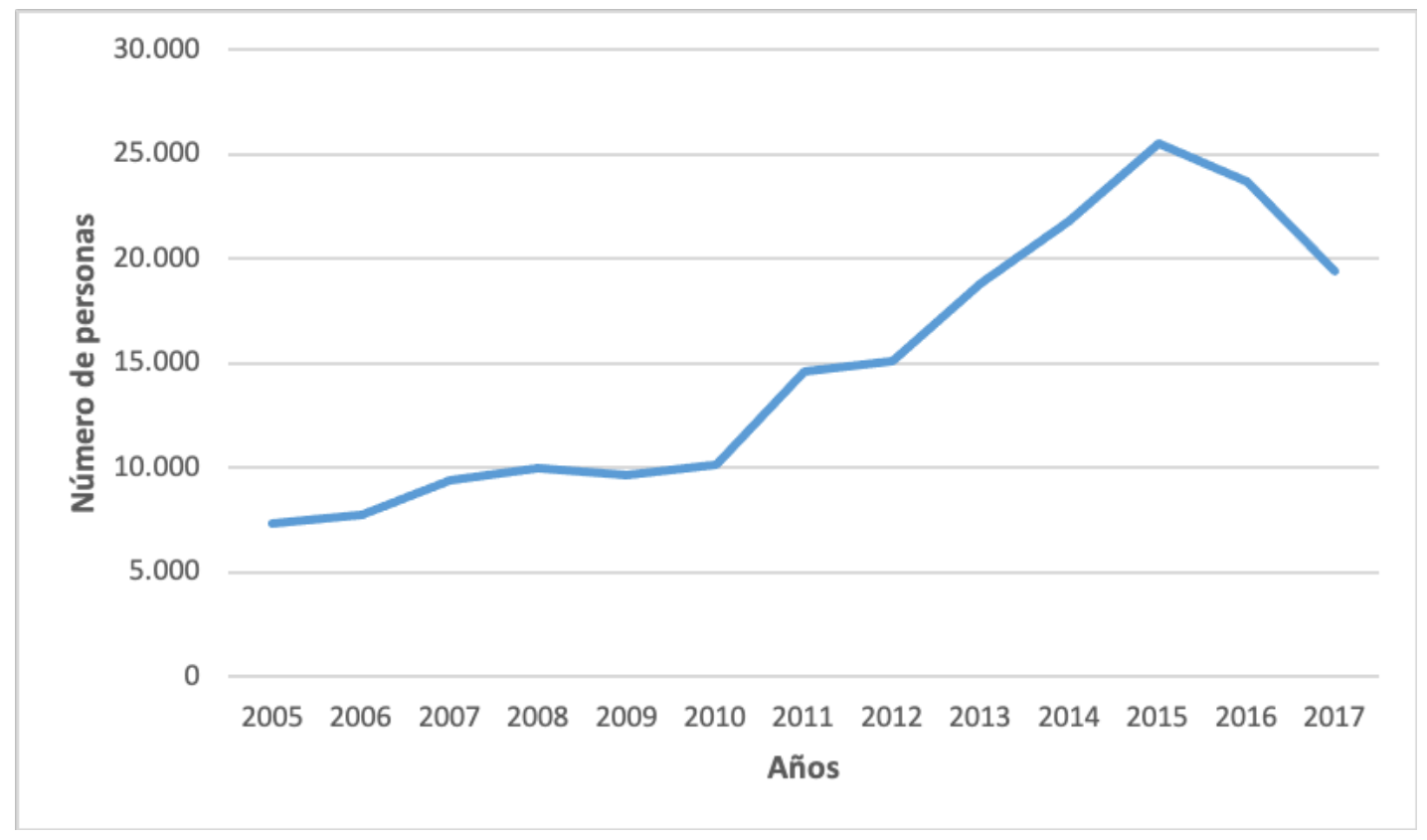

Fuente: Elaboración propia a partir de datos del INE. Estadística de Variaciones Residenciales (INE-E, 2017)

Así, como consecuencia de este dramático contexto, miles de jóvenes comenzaron a salir del país buscando superar el entorno de inestabilidad y falta de desarrollo profesional, al que se veían abocados en España, donde adaptaban sus proyectos vitales a empleos y formas de vida inestables, siendo incapaces de conseguir una identidad profesional consolidada que les permitiese poder plantearse un proyecto de vida propio (Standing, 2013). De esta forma, en los años más críticos de la recesión económica, esta nueva emigración española también conocida como migración neo- 
hispánica (Domingo et al., 2014), se dirigió principalmente hacia Europa (véase figura 2). Pero, llama la atención como la misma disminuyó de 2005 a 2014 en 12,5 puntos, mientras que los flujos que se dirigían hacia América se incrementaron en 11,9 puntos durante el mismo periodo temporal. Este dato manifiesta cómo el auge económico que muchos países americanos estaban experimentando en aquellos años (principalmente Perú, Colombia y Chile), sumado a la cercanía cultural que hace que la barrera idiomática no sea un obstáculo, propiciaron dicho incremento en los flujos migratorios de jóvenes españoles hacia América.

Figura 2. Evolución de las emigraciones de españoles de 25 a 34 años de edad a Europa y América (2005-2014)

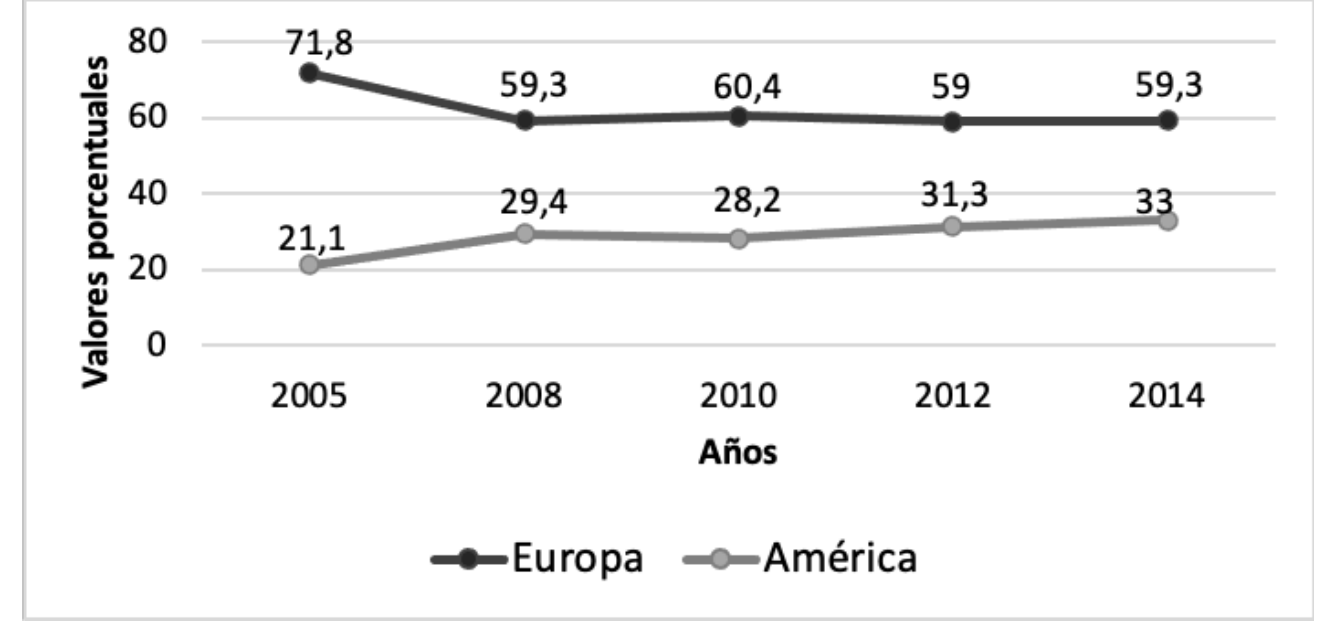

Fuente: Elaboración propia a partir de datos del INE. Estadística de variaciones residenciales (INE-E, 2014)

Así lo revela el estudio `Dinámicas migratorias en América Latina y el Caribe (ALC), y entre ALC y la Unión Europea' (Córdova, 2015) realizado por la Organización Internacional para las Migraciones (OIM), explicando que la mayor parte de la migración hacia América Latina procede de España. De esta manera, atendiendo a datos de dicho informe, en 2003 emigraron poco más de 7000 españoles hacia América Latina, cifra que se incrementó a 154000 personas en 2012. Según este estudio, el perfil de quienes emigran hacia ALC no corresponde con el de personas que retornan, sino con el de europeos cualificados que huyen del desempleo y la precariedad laboral. De este modo, se puede afirmar que la crisis económica ha provocado un importante cambio en el patrón migratorio global, de manera que se observa un aumento del flujo Europa-América Latina, en contraposición a un descenso de las migraciones latinoamericanas hacia Europa (Sassone y Yépez, 2014), esto, en parte también es debido al incremento del número de filiales (o empresas satélites) de corporaciones europeas en Latinoamérica, que al estar deslocalizadas en este territorio no han sufrido con tanta fuerza los efectos de la crisis y han atraído a personas cualificadas provenientes de Europa.

El Instituto Nacional de Estadística de España (INE-E), mediante la Estadística de Variaciones Residenciales (EVR), nos indica que entre 2008 y 2015 tuvieron lugar 196197 emigraciones de españoles hacia el continente americano (INE-E, 2015). Entre estas emigraciones destaca especialmente la de jóvenes universitarios hacia Chile (ocupando el tercer puesto en 2014 como destino de españoles de 25 a 34 años de edad, tras Estados Unidos y Ecuador), atraídos principalmente por su crecimiento económico, su desarrollo en infraestructuras, y su estabilidad política, que la convierten en una de las principales economías de América Latina. Así, según el Departamento de Extranjería y Migración de Chile (2013), en 2013 España se estableció como el quinto país 
emisor de población inmigrante (3,7 \%), tras Perú (29,7 \%), Bolivia (20,3\%), Colombia (20,2 \%) y Argentina (4,5\%).

Es importante destacar que las estadísticas ofrecidas por el INE-E, han de tomarse con cautela ya que no reflejan fielmente la realidad, esto es debido a que los datos oficiales sobre emigración española están basados únicamente en las bajas padronales, siendo necesario que los emigrados se den de alta en los consulados de España en el exterior. Una inscripción que, en la mayoría de los casos, no llega a producirse por los costes burocráticos y los nulos beneficios que conlleva (Rodríguez-Puertas, 2017: 42). Por estos motivos, como indica Gonzáles-Ferrer (2013), los datos del Padrón de Españoles Residentes en el Extranjero (PERE), del Censo Electoral de Residentes Ausentes (CERA) o de la Estadística de Variaciones Residenciales (EVR), no son un buen instrumento para conocer en profundidad el número de españoles emigrados, aunque sí suponen buenos indicadores generales que, en el caso del presente trabajo, nos ayudan a identificar una tendencia creciente en la emigración juvenil española. Sin embargo, pese a que la tendencia identificada es progresiva, es más probable que la emigración de españoles al exterior desde que se inició la crisis sea una cifra superior a la ofrecida por estas estadísticas.

Este hecho puede ser observado si comparamos las cifras proporcionadas por la EVR de España, y la estadística ofrecida por el Departamento de Extranjería y Migración de Chile ${ }^{3}$ (véase figura 3) basado en las visas otorgadas (estos datos, aunque tampoco son exactos al corresponder la información con actos administrativos y no tratarse de personas, nos permiten establecer la tendencia de la emigración española en Chile de forma más objetiva, al no omitir a las personas no registradas en el consulado). De esta manera, vemos como las cifras aportadas por el Ministerio del Interior de Chile son entre dos y tres veces mayores que las que indica el INE de España.

Figura 3. Emigración española a Chile. Comparación de las cifras de la EVR con las ofrecidas por el Departamento de Extranjería y Migración de Chile (2008-2015)

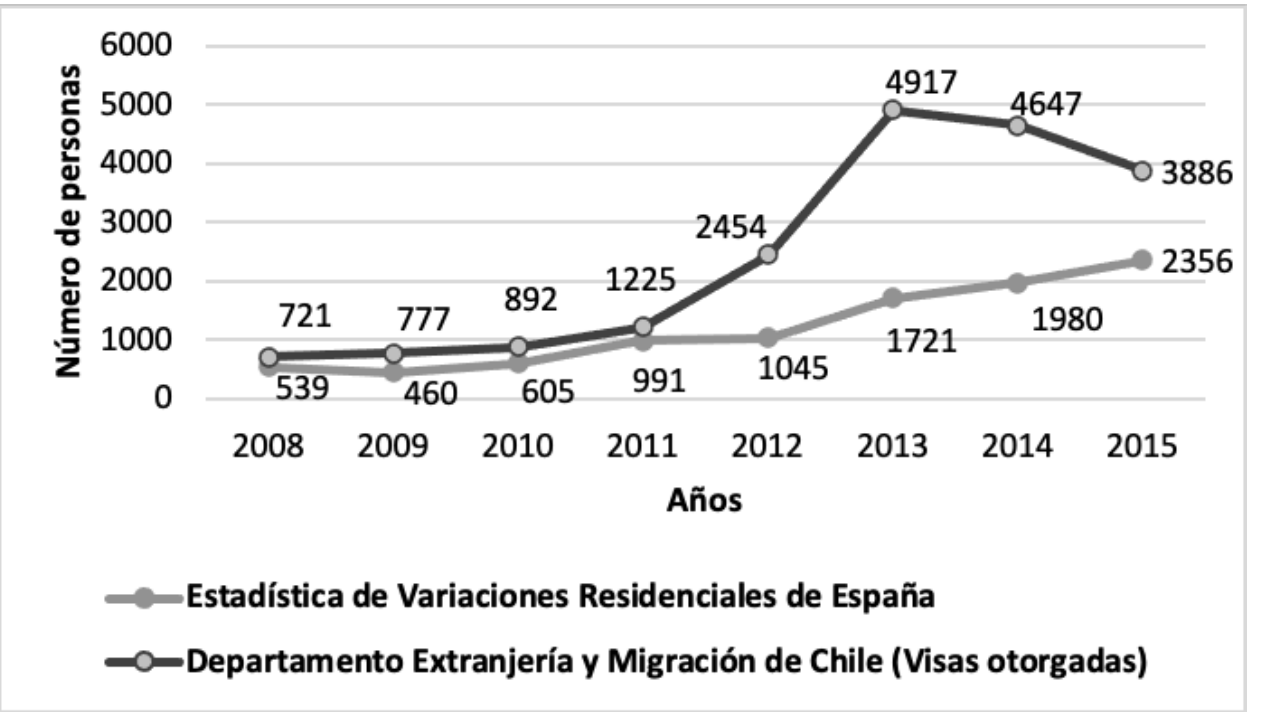

Fuente: Elaboración propia a partir de datos del INE (EVR) y del Departamento de Extranjería y Migración de Chile.

Como evidencian los datos, el número españoles que emigraron a Chile se incrementó considerablemente en los años de consolidación de la crisis (2010-2014). Este aumento de la emigración

3. Estas cifras, no publicadas, fueron proporcionadas en el marco de esta investigación por Claudia Silva Dittborn, Jefa de la Sección de Estudios en el Departamento de Extranjería y Migración de Chile. 
hacia el país latinoamericano, encuentra explicación en su relativamente baja tasa de desempleo, que se situaba en el 6,1 \% en 2013 (Instituto Nacional de Estadística de Chile, 2013), siendo en España del 26,9 \% para ese mismo año (INE-E, 2013), y principalmente, debido al fuerte ciclo expansivo del sector minero que se ha consolidado como el principal motor de la economía chilena, permitiendo la llegada de profesionales especializados en la minería, la geología, la energía y las nuevas tecnologías. Así, el incremento producido en la emigración española a partir del año 2010, responde, en buena medida, a la puesta en marcha de políticas de atracción de mano de obra cualificada por parte del gobierno chileno, con el objetivo de impulsar el ciclo de crecimiento de este sector. Alcanzando su auge en el año 2013, cuando diversos medios de comunicación españoles publicitaron que Chile ofrecería miles de puestos de trabajo especializados entre 2013 y 2020 (Rodríguez-Fariñas et al., 2015).

Podemos enmarcar esta emigración juvenil en las denominadas "migraciones norte-sur", es decir, se trataría de jóvenes cualificados del norte que emigran a las llamadas economías emergentes de los países del sur, en busca de oportunidades laborales que no encuentran en sus países de origen como consecuencia de la fuerte crisis económica (Docquier et al., 2010). Igualmente, también pueden encontrar explicación mediante la "Teoría del Sistema Mundial", donde autores como Saskia Sassen (2007), indican que la expansión de la globalización económica ha generado que las empresas dispersen parte de sus operaciones entre diferentes países, de esta forma, antes el lugar principal para cumplir estas operaciones era la sede central, mientras que actualmente existen otros lugares: aquellos que ocupan las empresas contratadas por la sede central para la realización de las funciones más complejas y/o especializadas. Esta organización de la economía global genera una fuerte interdependencia entre el conjunto de los países del mundo, incrementándose fuertemente las transacciones transfronterizas, la movilidad de mano de obra, recursos y conocimientos. Así, diversas empresas españolas del área de la construcción, las telecomunicaciones, la minería y la energía, cuentan con filiales en Chile y en diversos países latinoamericanos (Béjar, 2005), lo que facilita la expatriación de trabajadores españoles cualificados a estos países o la decisión migratoria de los mismos, cuando estas empresas españolas comienzan a verse afectadas por la crisis económica mientras que sus filiales en el extranjero permanecen estables.

Parece, pues, pertinente el objeto de este trabajo que analizará, por un lado, y a través de los datos proporcionados por el Departamento de Extranjería y Migración de Chile, las características de esta migración neohispánica en el país latinoamericano (realizando con esta intención un estudio descriptivo a partir de variables como el sexo de los migrantes, la región de Chile donde se ubican, los motivos migratorios, etc.) Y por otro, en este caso mediante el análisis de la información obtenida con 11 entrevistas en profundidad y un grupo de discusión a jóvenes residentes en el país, cómo afrontan y experimentan sus procesos migratorios y su inserción sociocultural en el nuevo entorno de acogida.

Para ello, en este texto se presenta un modelo tridimensional de gran utilidad para estudiar tales comportamientos, mostrándose en el apartado metodológico los procedimientos seguidos para la producción, codificación y análisis de los datos. Seguidamente, se exponen los diferentes resultados (tanto descriptivos como de índole cualitativa), y en último lugar, se establece la discusión y conclusiones sobre los mismos. 


\section{Nativofóbicos, nativofílicos e híbridos: nuevas tipologías de jóvenes migrantes}

A la hora de estudiar cómo experimentan la inserción en otros países los jóvenes protagonistas de esta migración neohispánica, existe un reciente modelo de carácter empírico, muy útil para comprender las transformaciones que acontecen en sus percepciones y subjetividades en el transcurso de sus procesos migratorios. Este modelo propuesto por Entrena-Durán y RodríguezPuertas (2017), diferencia tres categorías de análisis denominadas: Españofobia (o nativofobia); Españofilia (o nativofilia) e Identidad Híbrida. Así, atendiendo a estas categorías, el discurso migratorio (o necesidad de emigrar) surge en un dramático entorno para los jóvenes, en el que se ven condicionados por el malestar que les produce la escasez de expectativas y la incertidumbre vital, aspectos propios de un mercado de trabajo fuertemente precarizado (caracterizado por la temporalidad y las malas retribuciones). Así, estas nefastas condiciones les llevan a mostrar la llamada 'subjetividad nativofóbica' (determinada por la repulsa o rechazo hacia sus contextos de origen), que genera el desarrollo de una urgente necesidad de abandonar el país. Pero, dicha subjetividad nativofóbica experimenta una transformación en el momento que emigran y establecen contacto con la nueva sociedad de acogida, donde comienzan a sufrir la pérdida de sus relaciones sociales y espacios cotidianos de confort (aquellos que mantenían en la sociedad de origen y que estaban compuestos por sus familiares y amigos), lo que puede favorecer el surgimiento de dificultades de integración y/o adaptación a los nuevos entornos.

De esta manera, la nativofobia inicial puede evolucionar hacia una nativofilia que lleva a los migrantes a sentir una profunda nostalgia por su sociedad de origen. Se trata de un sentimiento de añoranza que puede incrementarse si no se superan las barreras migratorias que los jóvenes van encontrando en el nuevo país (percepción de discriminación, dificultad con el idioma, problemas con la adaptación al nuevo clima, etc.). Sin embargo, la progresiva superación de tales barreras puede propiciar una mayor integración social en destino, donde, si además el migrante logra un buen puesto de trabajo (acorde a sus cualificaciones), mejorando así su estatus con respecto al que ocupaba en la sociedad de origen, puede retomar la posición nativofóbica y aferrarse a la nueva sociedad por permitirle desarrollar una vida estable, a la vez que rechaza su propio país por no otorgarle dicha oportunidad.

Igualmente, la superación de los obstáculos migratorios puede favorecer que aparezca una identidad híbrida, a partir de la cual el migrante se percibe a sí mismo como parte de dos mundos: el de origen y el de llegada; identidad que, a menudo, puede generar crisis de arraigo o pertenencia. A continuación, se muestran las características de estas categorías analíticas (el discurso que producen, la identificación del migrante con el endogrupo o el exogrupo, las estrategias adaptativas que provocan, y en última instancia, la percepción que generan sobre la posibilidad de retornar a España). 
Tabla 1. Categorías discursivas en la identidad de los jóvenes emigrados.

\begin{tabular}{|c|c|c|c|}
\hline & Nativofobia & Nativofilia & $\begin{array}{l}\text { Nueva identidad híbrida entre } \\
\text { el mundo de partida y el de } \\
\text { acogida }\end{array}$ \\
\hline Discurso & $\begin{array}{l}\text { Son jóvenes que asimilan la } \\
\text { cultura dominante del malestar } \\
\text { y la frustración generada en } \\
\text { el actual contexto español, } \\
\text { interiorizando los valores } \\
\text { negativos en sus discursos y } \\
\text { llevando al extremo el malestar } \\
\text { social que perciben. }\end{array}$ & $\begin{array}{l}\text { Se trata de jóvenes a medio } \\
\text { camino entre dos realidades, } \\
\text { ya que, aunque se encuentran } \\
\text { desplazados físicamente, } \\
\text { siguen arraigados mentalmente } \\
\text { a sus orígenes. Por tanto, } \\
\text { aunque tienen una actitud } \\
\text { crítica hacia el contexto } \\
\text { español, no la canalizan en } \\
\text { una fobia, sino que muestran } \\
\text { nostalgia hacia aspectos de la } \\
\text { cultura española. }\end{array}$ & $\begin{array}{l}\text { Se trata de jóvenes que han } \\
\text { pasado una larga etapa en } \\
\text { el extranjero, de manera } \\
\text { que han experimentado una } \\
\text { aculturación que les lleva a } \\
\text { sentirse entre dos mundos, } \\
\text { lo que desemboca en el } \\
\text { surgimiento de una nueva } \\
\text { identidad: la del migrante. } \\
\text { Estos jóvenes muestran cierto } \\
\text { arraigo a su país de origen, } \\
\text { pero se sienten incómodos } \\
\text { cuando vuelven, debido al } \\
\text { proceso de distanciamiento } \\
\text { que han sufrido. }\end{array}$ \\
\hline Identificación & $\begin{array}{l}\text { Se identifican con el exogrupo } \\
\text { formado por la población } \\
\text { autóctona del país de destino, } \\
\text { mostrando alejamiento del } \\
\text { endogrupo de la sociedad } \\
\text { española de procedencia. } \\
\text { Así, en su discurso tratan de } \\
\text { asimilarse como ciudadanos } \\
\text { del país de destino. }\end{array}$ & $\begin{array}{l}\text { Se identifican con el endogrupo } \\
\text { formado por otros españoles } \\
\text { emigrados. Ello, como defensa } \\
\text { ante las fuertes barreras de } \\
\text { inserción que encuentran en la } \\
\text { nueva cultura. }\end{array}$ & $\begin{array}{l}\text { Al adquirir una identidad } \\
\text { transnacional y un tanto } \\
\text { cosmopolita, tienden a } \\
\text { identificarse con personas de } \\
\text { otros países que comparten } \\
\text { perfiles y problemas similares, } \\
\text { con las que tienen en común } \\
\text { el hecho de ser jóvenes con } \\
\text { elevada cualificación que } \\
\text { han emigrado buscando una } \\
\text { oportunidad laboral. }\end{array}$ \\
\hline $\begin{array}{l}\text { Estrategia de } \\
\text { adaptación }\end{array}$ & $\begin{array}{l}\text { En el país de destino, como } \\
\text { estrategia de adaptación, } \\
\text { tratan de evitar el contacto } \\
\text { con españoles dentro de su } \\
\text { grupo de iguales, a la vez que } \\
\text { procuran su rápida adaptación } \\
\text { a las costumbres locales. }\end{array}$ & $\begin{array}{l}\text { No buscan una adaptación a } \\
\text { la cultura del país de destino. } \\
\text { Su grupo de iguales suele } \\
\text { estar formado por otros } \\
\text { españoles emigrados, y tratan } \\
\text { de mantener las costumbres } \\
\text { españolas dentro del mismo. }\end{array}$ & $\begin{array}{l}\text { Al haberse formado en ellos } \\
\text { una identidad mixta y/o más } \\
\text { o menos cosmopolita, suelen } \\
\text { ser bastante abiertos a otras } \\
\text { culturas, de manera que su } \\
\text { grupo de iguales suele estar } \\
\text { formado por otros españoles } \\
\text { emigrados, jóvenes de otros } \\
\text { países y jóvenes autóctonos } \\
\text { del país de destino. }\end{array}$ \\
\hline $\begin{array}{l}\text { Posibilidad de } \\
\text { retorno }\end{array}$ & $\begin{array}{l}\text { En el discurso de estos } \\
\text { jóvenes aparece la idea del no } \\
\text { retorno, ya que identifican el } \\
\text { retorno como un fracaso de su } \\
\text { propósito inicial de desarrollar } \\
\text { un proyecto de vida estable en } \\
\text { el país al que han emigrado. }\end{array}$ & $\begin{array}{l}\text { Para estos jóvenes la vuelta es } \\
\text { necesaria, ya que mantienen } \\
\text { fuertes lazos de arraigo a su } \\
\text { país. Por ello, piensan en el } \\
\text { retorno, aunque con cierta } \\
\text { frecuencia lo posponen, } \\
\text { principalmente debido al } \\
\text { contexto de crisis económica } \\
\text { que sufre España. }\end{array}$ & $\begin{array}{l}\text { En su discurso no contemplan } \\
\text { el retorno definitivo, debido } \\
\text { a que han pasado una larga } \\
\text { etapa en el extranjero que ha } \\
\text { provocado su desadaptación } \\
\text { a la forma de vida española. } \\
\text { Así, cuando vuelven } \\
\text { ocasionalmente, se sienten } \\
\text { incómodos y no encuentran su } \\
\text { lugar. }\end{array}$ \\
\hline
\end{tabular}

Fuente: (Entrena-Durán y Rodríguez-Puertas, 2017: 71) 
Figura 4. Proceso de redefinición de la identidad en los jóvenes emigrados

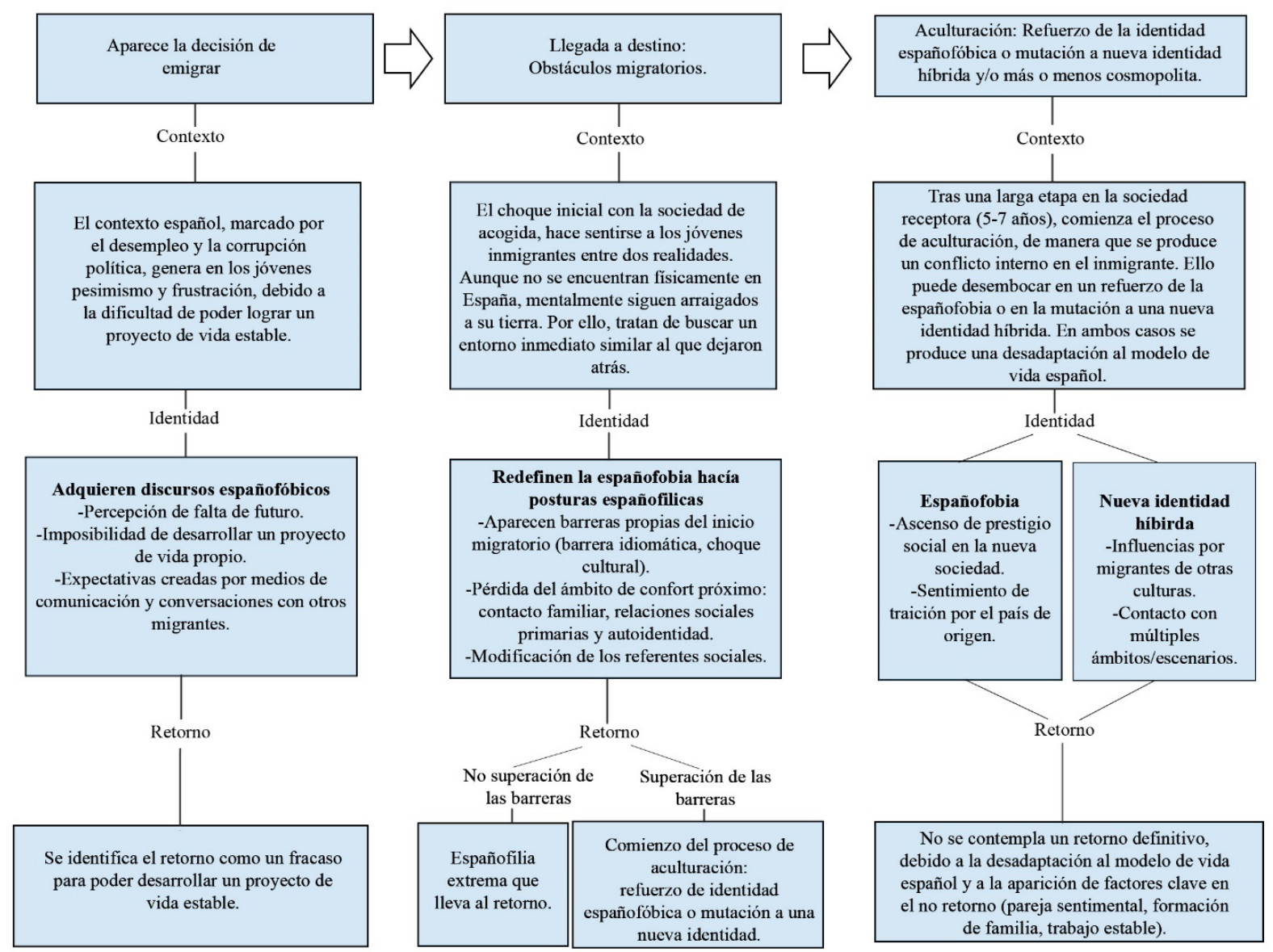

Fuente: (Entrena-Durán y Rodríguez-Puertas, 2017: 73)

\section{Metodología}

La presente investigación fundamentada en el trabajo de campo realizado en Santiago de Chile, entre marzo y junio de 2016, consta de dos fases metodológicas, así, en un primer lugar y a partir de los datos proporcionados por el Departamento de Extranjería y Migración de Chile, se elabora un análisis descriptivo de la nueva emigración española establecida en el país latinoamericano, basándose para ello en las visas de residencia otorgadas a ciudadanos españoles durante el periodo 2010-2015, siendo una muestra total de 18021 visas otorgadas en dicho periodo. Aunque como se ha mencionado anteriormente, estas cifras corresponden a datos de carácter administrativo y no a personas, son muy útiles para conocer las tendencias migratorias dentro del país, siendo el Departamento de Extranjería y Migración de Chile el principal organismo que cuantifica la entrada de población inmigrante en el territorio. Igualmente, la utilización de estas estadísticas impide que haya una sub-representación de los migrantes como si ocurre con las estadísticas del INE de España, que como se ha explicado, dependen principalmente de unos registros consulares que en la mayor parte de los casos no se llevan a cabo.

De esta manera, con la utilización de estos datos se realizó un análisis descriptivo, con el objetivo de conocer las características de los migrantes españoles en Chile, atendiendo para ello a una serie de variables como: el sexo, la edad, la profesión, la titularidad de la visa otorgada, los motivos 
para la obtención de la misma, así como la región o comuna donde se concedieron. Tales datos fueron muy importantes para establecer el perfil de los informantes a entrevistar, así, atendiendo a los mismos, y con la intención de comprender cómo eran los procesos migratorios y la adaptación de los jóvenes españoles afincados en la sociedad chilena, se realizaron 11 entrevistas en profundidad y un grupo de discusión, a españoles con una edad comprendida entre los 25 y 35 años $^{4}$, con titulación universitaria ${ }^{5}$, residentes en el área metropolitana de Santiago de Chile, y que llegaron al país entre 2010 y 2015 (véase tablas 2 y 3).

Tabla 2. Perfiles de los jóvenes entrevistados residentes en Chile

\begin{tabular}{|c|c|c|c|c|}
\hline Edad & Sexo & Tiempo residiendo en Chile & Formación & Profesión \\
\hline 34 & Hombre & 37 meses & $\begin{array}{l}\text { Licenciado en } \\
\text { Ciencias Políticas }\end{array}$ & $\begin{array}{l}\text { Consultor de formación } \\
\text { en compañía de } \\
\text { telecomunicaciones }\end{array}$ \\
\hline 26 & Mujer & 36 meses & $\begin{array}{l}\text { Licenciada en } \\
\text { Pedagogía }\end{array}$ & $\begin{array}{l}\text { Profesora de educación física en } \\
\text { escuela municipal }\end{array}$ \\
\hline 33 & Mujer & 26 meses & $\begin{array}{l}\text { Licenciada en } \\
\text { Psicología }\end{array}$ & $\begin{array}{l}\text { Encargada selección de } \\
\text { personal en gimnasio }\end{array}$ \\
\hline 29 & Mujer & 48 meses & $\begin{array}{l}\text { Licenciada en } \\
\text { Geología }\end{array}$ & $\begin{array}{l}\text { Hidrogeóloga en minera de } \\
\text { Iquique (norte de Chile) }\end{array}$ \\
\hline 30 & Mujer & 36 meses & $\begin{array}{l}\text { Licenciada en } \\
\text { Psicología }\end{array}$ & Investigadora postdoctoral \\
\hline 32 & Mujer & 49 meses & $\begin{array}{l}\text { Licenciada en } \\
\text { Sociología }\end{array}$ & $\begin{array}{l}\text { Socióloga en fundación servicio } \\
\text { jesuita a inmigrantes }\end{array}$ \\
\hline 29 & Hombre & 54 meses & Arquitectura Superior & Profesor en Universidad \\
\hline 35 & Hombre & 38 meses & Arquitectura Técnica & $\begin{array}{l}\text { Jefe de oficina en empresa de } \\
\text { ingeniería }\end{array}$ \\
\hline 27 & Hombre & 27 meses & $\begin{array}{l}\text { Diplomado en } \\
\text { Trabajo Social }\end{array}$ & $\begin{array}{l}\text { Asesor técnico de desarrollo } \\
\text { comunitario en Recoleta }\end{array}$ \\
\hline 35 & Hombre & 50 meses & $\begin{array}{l}\text { Ingeniaría Técnica } \\
\text { Industrial Eléctrica }\end{array}$ & $\begin{array}{l}\text { Ingeniero de Proyectos en } \\
\text { empresa de energías renovables }\end{array}$ \\
\hline 31 & Hombre & 38 meses & Arquitectura Técnica & Arquitecto técnico en oficina \\
\hline
\end{tabular}

Fuente: Elaboración propia

Como los datos procedentes del Departamento de Extranjería y Migración de Chile, mostraban que una parte importante de estos migrantes desarrollaban profesiones relacionadas con la ingeniería, la arquitectura y la geología, se trató de que parte de los mismos tuvieran ese perfil, así, se entrevistó a una profesional de la geología, a un arquitecto superior, a dos arquitectos técnicos y a un ingeniero industrial; igualmente, en el grupo de discusión también participaron dos arquitectos. Por otro lado, se decidió entrevistar a jóvenes cualificados en otras áreas como las ciencias sociales, para tratar de conocer si el discurso de los informantes difería atendiendo a la profesión desempeñada. En este caso, hay que indicar que la profesión desarrollada no suponía modificaciones en los discursos ni en el tipo de inserción sociocultural seguida en el contexto chileno, ya que, como veremos a lo largo de este trabajo, la mayor parte de los informantes (inde-

4. Se seleccionó este tramo de edad porque, atendiendo a la Estadística de Variaciones Residenciales, el intervalo de 25 a 34 años, es el que mayor porcentaje de salidas al exterior registraba (en torno al $30 \%$ en todos los años del periodo 2010-2015) en comparación con las demás edades (INE-E, 2015).

5. Además de que los datos del Departamento de Extranjería de Chile indicaban que una parte importante de las visas de residencia otorgadas correspondían con solicitudes de profesionales técnicos, diversos barómetros de opinión en España (CIS, 2012; Real Instituto Elcano, 2013) mostraban que en los años más dificultosos de la recesión económica, los jóvenes españoles más predispuestos a emigrar eran aquellos que poseían estudios universitarios medios y superiores. 
pendientemente de su profesión) seguían la explicada en el epígrafe anterior como `adaptación nativofílica'.

Es importante indicar que se utilizaron ambas técnicas de producción de datos (entrevistas en profundidad y grupo de discusión) de manera complementaria, así, con la finalidad de mejorar la información de carácter individual en torno a los procesos de inserción sociocultural, obtenida mediante las entrevistas, se constituyó un grupo de discusión que permitió conocer también las percepciones de carácter colectivo (percepciones sobre las sociedades de origen y de acogida), que los informantes mostraban y desarrollaban en la sociedad chilena.

Tabla 3. Perfiles de los jóvenes participantes en el grupo de discusión realizado en Chile

\begin{tabular}{|l|l|l|l|l|}
\hline Edad & Sexo & Tiempo residiendo en Chile & Formación & Profesión \\
\hline 25 & Mujer & 14 meses & Licenciada en Derecho & $\begin{array}{l}\text { Abogada en estudio } \\
\text { de ingeniería civil }\end{array}$ \\
\hline 34 & Mujer & 24 meses & Licenciada en Derecho & $\begin{array}{l}\text { Directora servicios } \\
\text { sociales comunitarios }\end{array}$ \\
\hline 32 & Hombre & 53 meses & Licenciado en Historia & $\begin{array}{l}\text { Jefe territorial servicios } \\
\text { sociales }\end{array}$ \\
\hline 29 & Mujer & 37 meses & $\begin{array}{l}\text { Licenciada en } \\
\text { Geografía }\end{array}$ & $\begin{array}{l}\text { Directora Regional en } \\
\text { Fundación Superación } \\
\text { Pobreza }\end{array}$ \\
\hline 31 & Mujer & 33 meses & $\begin{array}{l}\text { Licenciada en } \\
\text { Psicología }\end{array}$ & $\begin{array}{l}\text { Profesional Servicios } \\
\text { sociales comunitarios }\end{array}$ \\
\hline 30 & Hombre & 46 meses & Arquitectura Superior & $\begin{array}{l}\text { Encargado } \\
\text { Departamento de } \\
\text { proyectos }\end{array}$ \\
\hline 29 & Hombre & 50 meses & $\begin{array}{l}\text { Arquitectura Superior } \\
\text { Urofesor en }\end{array}$ \\
\hline
\end{tabular}

Fuente: Elaboración propia

\subsection{Técnicas de investigación}

Las técnicas de investigación utilizadas para la producción de los datos analizados en este trabajo han sido la entrevista en profundidad y el grupo de discusión. Así, como se ha explicado en el apartado anterior, con el objetivo de conocer cómo son los procesos migratorios y la inserción social de los jóvenes emigrados a Chile entre 2010 y 2015, se realizaron 11 entrevistas en profundidad y un grupo de discusión (en el que participaron siete personas) a jóvenes residentes en el país latinoamericano.

Tales entrevistas tuvieron una duración aproximada de 70 minutos, y el grupo de discusión de 90 minutos. Ambas técnicas de investigación se fundamentaron en un guion cuyo objetivo era recopilar relatos de vida sobre la manera en que los jóvenes migrantes experimentaban sus propios procesos migratorios en la sociedad chilena. Así, dicho guion seguía una serie de planteamientos que se pueden clasificar en las siguientes temáticas: perfiles sociodemográficos, experiencias de vida y de inserción sociocultural, así como las percepciones sobre la posibilidad de retornar a España. 


\subsection{Procedimientos para la producción de los datos}

Las entrevistas y el grupo de discusión se realizaron de forma presencial en la Universidad Alberto Hurtado de Santiago de Chile, en una sala habilitada para ello. El contacto con parte de los informantes se realizó previamente a la estancia de investigación, una vez que se conocían los resultados del análisis descriptivo efectuado con los datos que el Departamento de Extranjería proporcionó para este estudio, así, una vez orientado el perfil de los informantes, dicho contacto se llevó a cabo mediante anuncios en plataformas y foros de jóvenes españoles en Chile, tales como Marea Granate Chile, Españoles en Santiago de Chile (grupo de Facebook) y Spaniards (comunidad virtual de españoles migrantes), por otro lado, también se consiguió la colaboración de más participantes mediante el proceso conocido como muestreo bola de nieve (Valles, 2003), es decir, contando con la colaboración de los propios entrevistados para conseguir identificar a otros informantes cercanos a ellos que contaran con características importantes para la investigación.

\subsection{Análisis de los datos}

Para el análisis de los datos se emplearon las categorías analíticas del modelo tridimensional, explicado anteriormente en el segundo apartado, y que consta de tres códigos fundamentales: Nativofobia, Nativofilia e Identidad Híbrida. Para ello, se utilizaron los procedimientos propios de la Grounded Theory (Glasser y Strauss, 1967; Strauss y Corbin, 1990), con la intención de ordenar la información proveniente de los entrevistados en las antedichas categorías precodificadas. Así, con la utilización del software Atlas.Ti6, se fueron fragmentando dentro de cada una de las categorías los discursos producidos en las entrevistas y el grupo de discusión. Dicha tarea ayudó a comprender el patrón subyacente en los discursos de los jóvenes, conociendo, en última instancia, si seguían unos procesos de inserción social marcados por el rechazo a la sociedad española (nativofobia), por la fuerte nostalgia hacia la misma (natovifilia), o si debido a sus experiencias migratorias, desarrollaban una identidad híbrida basada en el cosmopolitismo o la falta de identidad territorial. Por tanto, las entrevistas siguieron un guion cuyo objetivo fue el de conocer cómo estos migrantes percibían su inserción sociocultural en la sociedad chilena, y qué estrategias de adaptación seguían, es decir, si mostraban un rechazo hacia sus contextos de origen por no haber podido desarrollar en los mismos un proyecto de vida, a la vez que sentían un apego por la sociedad chilena que sí les había brindado la oportunidad de desarrollarse profesionalmente (inserción nativofóbica), o si por el contrario, sentían una fuerte nostalgia por los espacios vitales que dejaron atrás, como respuesta ante la dificultades experimentadas en el nuevo entorno (inserción nativofílica), igualmente, se trataba de conocer si desarrollaban la tipificada como 'inserción híbrida', adquiriendo una identidad mixta conformada tanto por aspectos de la sociedad de origen como de la nueva sociedad, que les llevara a desarrollar, en última instancia, un sentimiento de pertenencia de índole más cosmopolita.

Así, tras diferenciar estas tres categorías de inserción sociocultural (nativofóbica, nativofílica e híbrida), se comenzó el trabajo de campo con la intención de indagar sobre las mismas, alcanzado la saturación teórica tras la realización de once entrevistas en profundidad y un grupo de discusión ${ }^{6}$.

Se plantea la utilización de la Grounded Theory, debido a que el presente trabajo trata de analizar unos resultados partiendo del objetivo general, de conocer y explicar cómo se produce la inser-

6. Entendiendo por saturación teórica el punto en que las nuevas entrevistas no aportan información adicional relevante de cara al objetivo sobre el que se quiere indagar (Ardila y Rueda, 2013). 
ción sociocultural de los jóvenes españoles residentes en la sociedad chilena, pero, sin introducir el sesgo que supondría el partir de hipótesis previas. Igualmente, es la metodología más apropiada para facilitar la libre expresión de los migrantes, y, a raíz de sus discursos y experiencias, desvelar de manera aproximativa cómo construyen tales procesos de inserción en los nuevos entornos a los que acceden.

\section{Resultados establecidos a partir de los datos proporcionados por el Departamento de Extranjería y Migración de Chile}

\subsection{Análisis descriptivo: particularidades sociodemográficas de la nueva emigración española en Chile}

Como se ha indicado en el apartado metodológico, este primer epígrafe correspondiente a la parte de resultados, está basado en los datos proporcionados por el Departamento de Extranjería y Migración de Chile (conseguidos gracias a la colaboración de Claudia Silva Dittborn, Jefa de la Sección de Estudios perteneciente al Departamento de Extranjería y Migración del Ministerio del Interior y Seguridad Pública de Chile). Así, atendiendo a estos datos compuestos por las visas de residencia otorgadas durante el periodo 2010-2015, se puede afirmar, en primer lugar, que en dicho periodo se registraron un total de 18021 visas concedidas a migrantes con nacionalidad española, incrementándose de 892 en 2010 a 3886 en 2015, y siendo los años 2013 y 2014, en los que mayor emigración española se registró con un total de 9564 visas de residencia emitidas (véase figura 1 del epígrafe 1).

De esta manera, en estos seis años analizados, España se convirtió en el quinto país emisor de población inmigrante a Chile, tras Perú, Bolivia, Colombia y Argentina. Al analizar por sexo esta emigración, se observa que es principalmente masculina (64 \% hombres y $36 \%$ mujeres). Este dato puede encontrar explicación en la predominante emigración de profesionales técnicos, así, por orden de importancia las profesiones más destacadas en este periodo son: ingenierías (12,7 $\%)$, siendo mayoritarias la civil y la industrial, la arquitectura $(4,7 \%)$ y la geología $(2 \%)$. Se trata de profesiones masculinizadas muy vinculadas al fuerte crecimiento de la minería y la construcción experimentado por Chile en los últimos años ${ }^{7}$.

En cuanto a la edad (véase gráfico 4), en cada uno de los años analizados, se puede observar como esta emigración se concentra principalmente en el tramo de 30 a 44 años, seguido por el de 15 a 29. Este dato nos indica que estamos ante una emigración de carácter laboral, ya que se produce en un tramo de edad de finalización educativa y/o entrada al mercado de trabajo (edad adulta).

Esta hipótesis se confirma al observar el carácter o los motivos por los cuales se otorgaron las visas (véase figura 6). Así, en todos los años del periodo 2010-2015, aparece el empleo como el principal motivo para la obtención de la misma. Por tanto, atendiendo a la profesión, el tramo de edad, el sexo, y los motivos para obtener la visa, podemos afirmar que estamos ante una emigración económica (mayoritariamente masculina) de personas cualificadas en las áreas de la ingeniería, la arquitectura y la geología.

7. Como explica Ana M. González (2014), existe una escasa presencia de mujeres españolas en profesiones técnicas y de ingeniería (tanto en España como en el exterior). Circunstancia que responde, principalmente, a la fuerte masculinización de las carreras tecnológicas y de ingenierías en España. 
Figura 5. Visas de residencia otorgadas a ciudadanos españoles según grupos de edad (2010-2015)

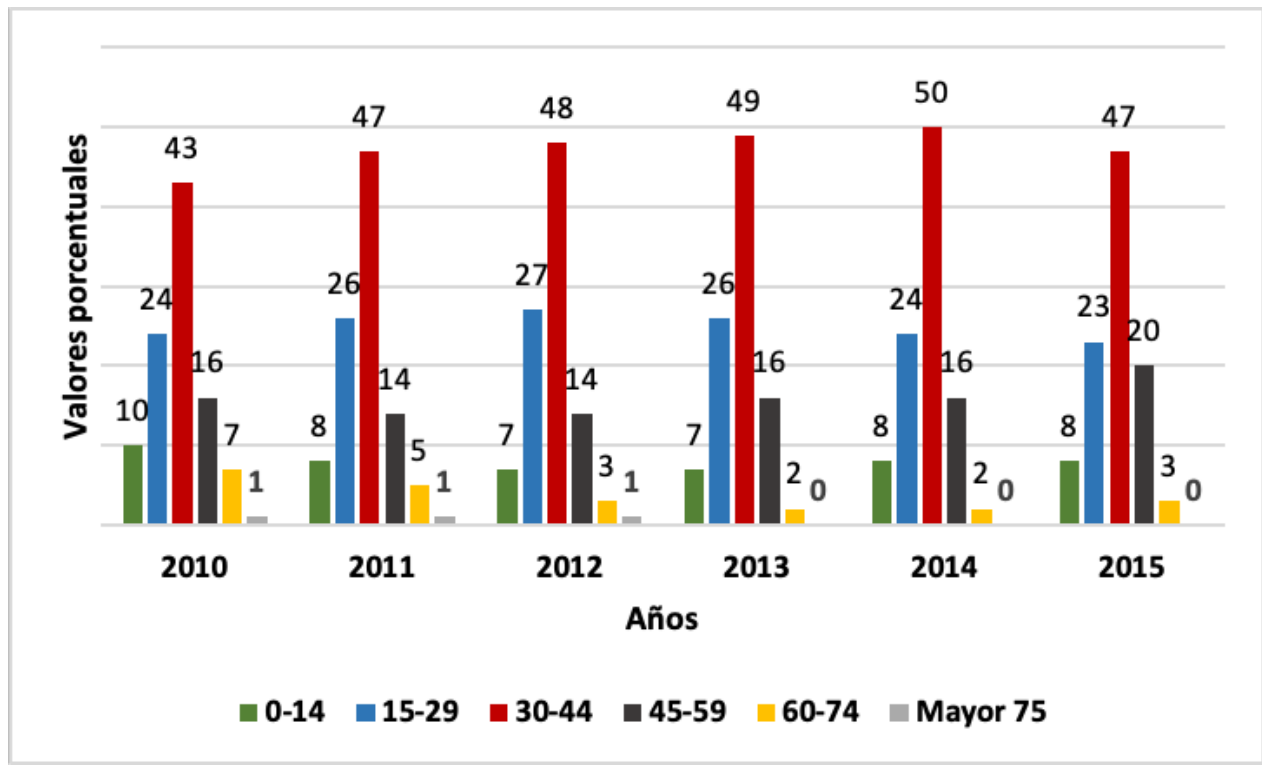

Fuente: Elaboración propia a partir de datos del Dpto. de Extranjería y Migración de Chile.

Figura 6. Principal motivación para la obtención de la visa en ciudadanos españoles

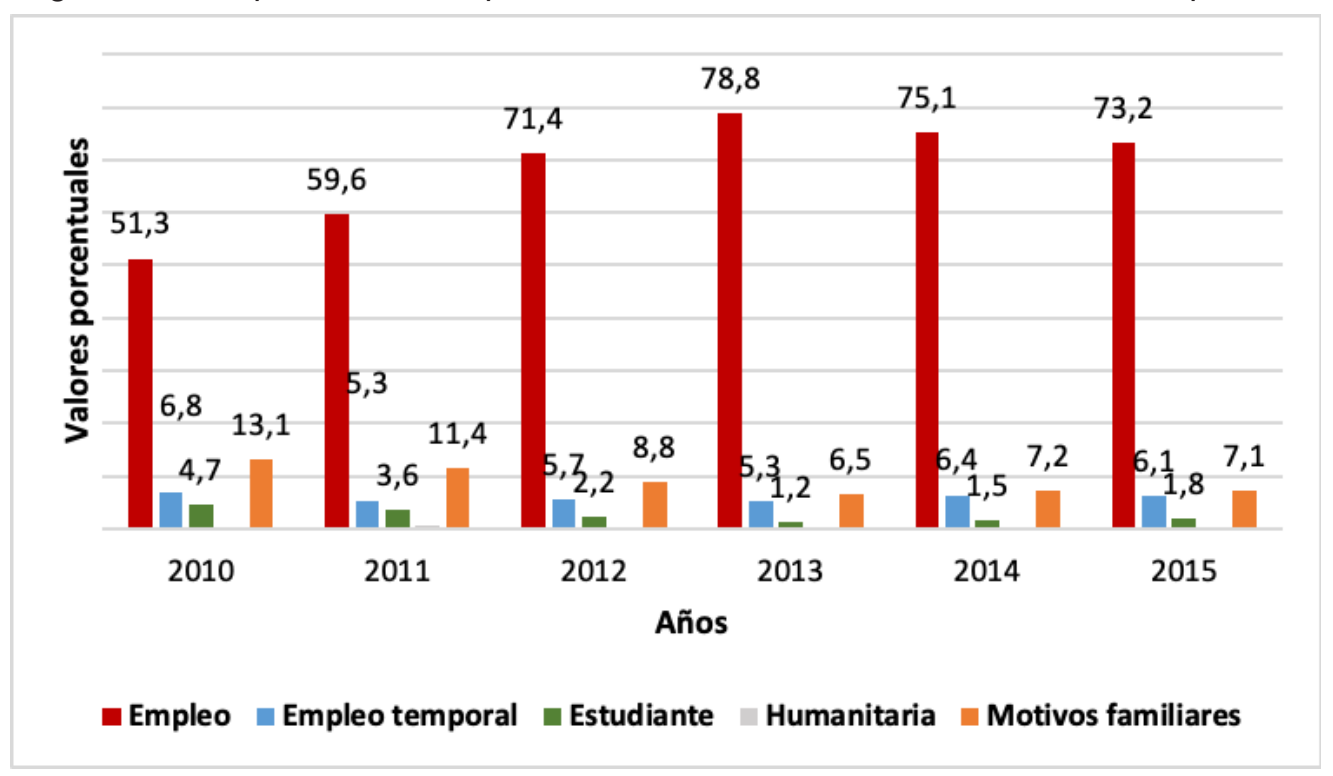

Fuente: Elaboración propia a partir de datos del Dpto. de Extranjería y Migración de Chile.

Otro dato importante a la hora de caracterizar esta emigración es la titularidad de las visas, así, el $88 \%$ de estas residencias son otorgadas a titulares (frente a un escaso $12 \%$ de dependientes), lo que nos indica que se trata de una emigración de jóvenes sin familia (es decir, que en su mayor parte no migran con hijos o menores dependientes). Por otro lado, si atendemos al espacio geográfico donde se ubican las residencias ligadas a las visas otorgadas, en todos los años que componen el periodo analizado (2010-2015), la mayor parte de las mismas (en torno al 70\%) se concedieron en la región metropolitana. Dentro de esta región, y como puede observarse en la figura 7, la mayor parte de los españoles emigrados se concentran en las comunas de Las Condes $(24,5 \%)$, Santiago $(15,4 \%)$ y Providencia $(14,7 \%)$. 
En dicho mapa se puede observar la manera en que se dispersan los diferentes grupos socioeconómicos entre las distintas comunas de la región metropolitana (siguiendo la clasificación estandarizada en Chile y conocida como "grupos ABCDE"), y el porcentaje de residencias otorgadas a españoles en cada una de ellas. Antes de analizar cómo es la dispersión de los ciudadanos españoles, es necesario explicar de qué manera se realiza esta clasificación de clases sociales, de dónde proviene, y qué influencia social tiene.

Figura 7. Distribución porcentual de los españoles emigrados a la región metropolitana de Santiago de Chile en el periodo 2010-2015, según grupos socioeconómicos ABCDE

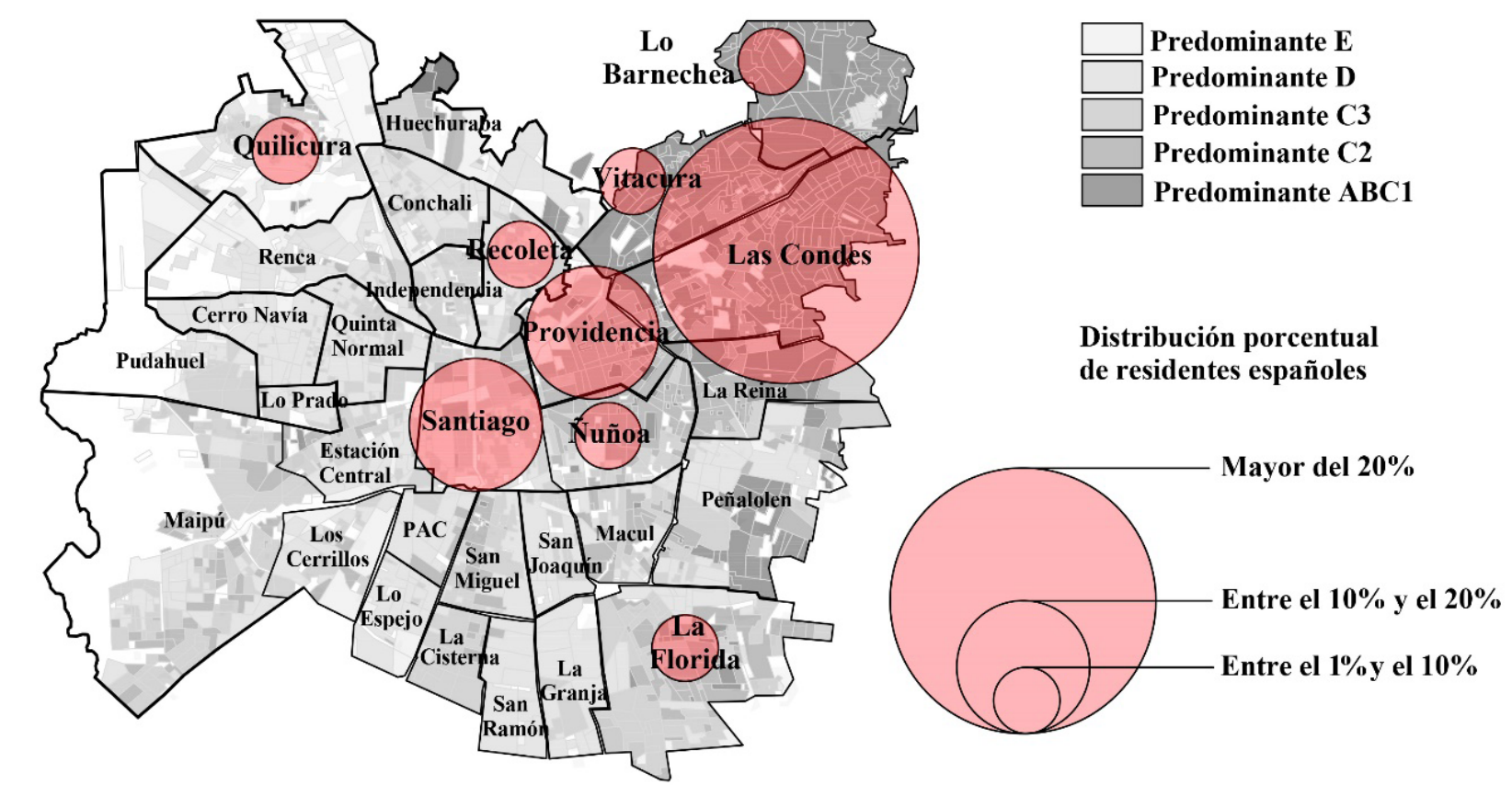

Grupos socioeconómicos

\begin{tabular}{|c|c|c|c|}
\hline PREDOMINANTE ABC1 & 29 & PREDOMINANTE C2 & 34,6 \\
\hline Las Condes & 24,5 & Santiago & 15,4 \\
\hline Vitacura & 2,4 & Providencia & 14,7 \\
\hline Lo Barnechea & 1,3 & Ñuñoa & 3,5 \\
\hline La Reina & 0,4 & Macul & 0,4 \\
\hline Peñalolen & 0,4 & $\begin{array}{l}\text { San Miguel } \\
\text { San Joaquín }\end{array}$ & 0,4 \\
\hline PREDOMINANTE C3 & 2,2 & PREDOMINANTE D & 3,1 \\
\hline Maipú & 0,7 & Quilicura & 1 \\
\hline Estación Central & 0,4 & Recoleta & 1 \\
\hline Pudahuel & 0,3 & Huechuraba & 0,6 \\
\hline Quinta Normal & 0,2 & Conchali & 0,2 \\
\hline Los Cerrillos & ? & Independencia & 0,2 \\
\hline & & Renca & 0,1 \\
\hline Cerro Navia & 0,1 & PREDOMINANTE E & 1,4 \\
\hline Lo Prado & 0,1 & La Florida & 1 \\
\hline Lo Espejo & 0,1 & La Cisterna & 0,2 \\
\hline Pedro Aguirre Cerda (PAC) & 0,1 & $\begin{array}{l}\text { La Granja } \\
\text { San Ramón }\end{array}$ & 0,1 \\
\hline
\end{tabular}

Fuente: Elaboración propia a partir de datos del Dpto. de Extranjería y Migración de Chile y del plano de Santiago, según grupos socioeconómicos predominantes presente en el libro Santiago Contemporáneo (Greene et al., 2011). 
Esta clasificación conocida como "ABCDE" normalizada en la sociedad chilena y adoptada de los estudios de mercado (Joignant y Güell, 2009), explica las características de los diferentes grupos socioeconómicos de la siguiente manera:

1. Nivel socioeconómico alto ABC1 (alto-alto) C1 (alto-bajo): Se trata de profesionales universitarios con carreras de prestigio que poseen altos puestos ejecutivos, suelen vivir en zonas con áreas verdes, bien pavimentadas y limpias, en casas o departamentos muy amplios. Son personas que se ubican principalmente en las comunas de Las Condes, Lo Barnechea y Vitacura.

2. Nivel socioeconómico C2 (clásica clase media): En este caso se trata de profesionales universitarios con carreras de nivel medio que trabajan como ejecutivos o directores de departamentos. Viven en zonas tradicionales alejadas del centro, en comunas como Las Condes, Providencia, La Reina, Nuñoa, La Florida y Macul.

3. Nivel socioeconómico C3 (clase media-baja): Este grupo corresponde a personas sin estudios de nivel superior, como pueden ser comerciantes, administrativos, vendedores, etc. Se ubican en comunas como San Joaquín, Independencia, Peñalolen, Lo Florido y Maipú.

4. Nivel socioeconómico D (clase baja): Son personas sin estudios o con estudios de nivel bajo, viven en zonas populares con una elevada densidad de población, en pequeñas viviendas y en áreas con malas infraestructuras. Suelen ubicarse en las comunas de Cerro Navia, Recoleta, Conchali y El Bosque.

5. Nivel socioeconómico E (extrema pobreza): Se trata de personas con pocos años de escolaridad que realizan trabajos ocasionales como lavar coches, venta ambulante, etc. Viven en sectores con altos índices de delincuencia en comunas como La Pintana, Huechuraba, Renca y Lo Espejo.

El propósito principal de esta clasificación mercantil es segmentar a la población en base a su capacidad de consumo, con el objeto de orientar las estrategias de mercado de las empresas (Cabezas, et al., 2011). El problema reside en que esta clasificación ha dado lugar a un fuerte 'urbanismo de mercado' afectando a los imaginarios sociales de la población que vive en el área metropolitana, de esta manera, como se observa en el mapa, el sector nor-oriente (Vitacura, Las Condes, Lo Barnechea, Peñalolen y La Reina) se consolida como la zona rica (ABC1), predominando en él las zonas verdes, centros culturales y de ocio, y mejores infraestructuras. En contraposición al sector sur-oriente (La Pintana, Puente Alto, La Florida, El Bosque, La Granja, San Ramón y La Cisterna), que se establece como la zona pobre (predominante E) con peores infraestructuras, sin zonas verdes, y alejada de los centros culturales y de ocio.

Así, el urbanismo aplicado en el área metropolitana de Santiago a través de políticas neoliberales de mercado, ha construido una ciudad desigual que afecta a los propios ciudadanos (que conviven separados según su estatus social), impregnándose de la mentalidad de la categorización y la clasificación. En este caso, los propios profesionales españoles que llegan a la ciudad, aunque como veremos más adelante tienden a denunciar este clasismo, lo reproducen inconscientemente por su fuerte arraigo social, como así muestra uno de los jóvenes entrevistados en Santiago de Chile:

Al llegar nos establecimos en una zona más central, pero los propios compañeros de trabajo nos decían que era peligroso, que no era una zona propia para profesionales, que había 
mucha delincuencia (...). Por eso nos terminamos mudando a Las Condes, que realmente es un sitio más seguro y más bonito. (Investigadora posdoctoral, 30 años, Chile).

De esta manera, si atendemos a la figura 7, podemos ver como los españoles emigrados en el periodo 2010-2015, se distribuyen principalmente en las zonas consideradas como clase media alta (en la zona residencial $\mathrm{ABC} 1$, encontramos un $29 \%$ ) y clase media (en la zona considerada como $\mathrm{C} 2$, encontramos un 34,6 \%). Así, la principal comuna en la que residen los españoles emigrados es Las condes, con un $24,5 \%$ de visas de residencia otorgadas en esta zona, siendo una de las principales comunas vinculadas a la clase social alta. En segundo lugar tenemos Santiago con un $15,4 \%$ de visas otorgadas (clase media C2), y por último, Providencia con un 14,7 \% (clase media C2). Por tanto, podemos decir que existe una segregación espacial de la población española en Santiago, en torno a la zona centro y nor-oriente de la región metropolitana.

Esta segregación responde, en parte, a que estos migrantes suelen ocupar profesiones relacionadas con la formación universitaria, como así lo indican los datos proporcionados por el Departamento de Extranjería y Migración de Chile (como se vio anteriormente, una parte significativa de las visas otorgadas, se corresponden con trabajos relacionados con la ingeniería, la arquitectura y la geología). Este desempeño de profesiones de carácter más cualificado lleva a estos migrantes a ser percibidos (y a percibirse a sí mismos) como grupos socioeconómicos de mayor nivel, lo que junto a la anteriormente mencionada 'mentalidad de la categorización' (fuertemente arraigada en la sociedad chilena), predispone a gran parte de los mismos a ubicarse en tales zonas.

\section{Resultados fundamentados en las entrevistas en profundidad y el grupo de discusión}

\subsection{Sentimiento de exilio como factor migratorio}

Los motivos que han llevado a estos jóvenes a emigrar, como bien explica el modelo tridimensional (integrado por las categorías: nativofobia, nativofilia e identidad híbrida) expuesto en los apartados anteriores, están ligados principalmente a su interacción en un contexto de frustración y pesimismo, entorno en el que, o bien se encontraban desempleados, o en el mejor de los casos desarrollaban trayectorias laborales precarias. Así, este dramático contexto donde los jóvenes no son capaces de adquirir una identidad laboral sólida y estable, a través de la cual poder insertarse correctamente en la vida socioeconómica, se convierte, en última instancia, en una fuerte motivación para desarrollar un férreo discurso migratorio:

Una vez que finalicé mi master en hidrogeología, la empresa donde trabajaba de prácticas me ofreció un contrato, pero con un sueldo ridículo, y me dije: no, esto es un engaño, acabo de terminar los estudios y no voy a quedarme en Madrid con este sueldo. Posteriormente encontré otro trabajo en Santander, pero únicamente por cuatro horas a la semana y un sueldo de risa. Entonces pensé: ya está, quedarse en España es perder mi futuro. Y empecé a buscar empleo por todo el mundo, me di cuenta que no tenía otra opción que la de emigrar. (Geóloga, 29 años).

Se trata de un discurso en el que los propios migrantes se autoperciben como "exiliados económicos", argumentando que no se marchan con la intención de conocer mundo o tener una vida cosmopolita, sino que lo hacen por culpa de unos gobernantes que no han sabido gestionar adecuadamente la crisis económica: 
Yo no me fui para conocer mundo, yo soy una exiliada. Yo hoy siento la obligación de estar en Chile, no la posibilidad de elegir si estoy o no. Hoy día no veo posibilidad de volver, porque volver sería trabajar en algo que no me corresponde, estar en casa de mis padres y tener mucha más inestabilidad de la que aquí ya tengo. (Profesora en escuela municipal, 26 años).

Aunque emigré voluntariamente, estuve un año y medio buscando trabajo y sólo me salían contratos inseguros, así que no sé si me marché realmente por quería, o casi por necesidad y obligación, por tratar de escapar de un país en el que los políticos administran una crisis recortando al ciudadano y ofreciéndonos unos salarios absurdos. (Geóloga, 29 años).

\subsection{Facilidad de adaptación en los migrantes españoles como consecuencia de una xenofilia hacia lo europeo-occidental}

Generalmente, los migrantes españoles residentes en Chile experimentan una inserción sociocultural sencilla y exenta de problemas. Esto responde a la existencia en el imaginario social de lo que podríamos denominar como: fuerte 'xenofilia hacia lo europeo-occidental'. Se trata de un imaginario en el que las personas de procedencia europea, son mejor valoradas en comparación con aquellas que provienen de territorios más próximos como Bolivia, Perú, o Colombia. Se trata de un hecho que ponen de manifiesto los propios migrantes españoles:

En Chile si eres español te valoran mejor que a otras nacionalidades. En esta sociedad existen niveles de inmigrantes, mi pareja, por ponerte un caso, es boliviana y ella sí ha sufrido discriminación. Sin embargo, un español siempre va a ser mejor considerado que un argentino, y un argentino o un uruguayo siempre van a ser mejor considerados que un mexicano, y un mexicano que un colombiano, un colombiano mejor que un peruano, y un peruano mejor que un boliviano, por lo tanto, existen niveles. Es muy sencillo, según tu piel y tu procedencia, serás considerado como buen o mal inmigrante. (Consultor en empresa de telecomunicaciones, 34 años).

Los españoles y las personas que vienen de Europa o Estados Unidos, en general, se perciben como una migración provechosa. Se nos ve como más competentes y serios, más formados. Eso no les pasa a los inmigrantes que vienen de Bolivia, de Haití, de Perú o de Colombia. (Investigadora postdoctoral, 30 años).

Esta xenofilia hacia lo europeo se puede apreciar en recientes estudios como Bitacora Social ${ }^{8} 2$ : ¿Aceptación o discriminación en Chile? (Ubilla et al., 2015: 4). En dicho estudio en el que se entrevistaron a personas pertenecientes a las 73 comunas urbanas (con más de cincuenta mil sujetos que representan el 70,9 \% del país), se muestra la percepción que tienen los chilenos hacia los inmigrantes dependiendo de su procedencia. De esta manera, aquellos inmigrantes percibidos con mala o muy mala imagen, son por orden de importancia: los bolivianos (34\%), los peruanos (30 \%) y los colombianos (22\%). Mientras que aquellos que son percibidos con una imagen muy positiva, serían: los brasileños $(84 \%)^{9}$, los alemanes (76 \%), los norteamericanos $(75 \%)$ y los españoles (74 \%). Así vemos como, paradójicamente, los ciudadanos con los que se comparte

8. Se trata de la segunda edición de un proyecto académico muy popular, creado por profesores e investigadores de la Universidad Autónoma de Chile en el año 2014, con la intención de generar investigaciones enfocadas a comprender la actualidad chilena desde las Ciencias Sociales.

9. Esta valoración positiva de la población brasileña en Chile, puede responder a las buenas relaciones migratorias existentes entre ambos países, así, actualmente, la inmigración Chilena en Brasil constituye la segunda comunidad de chilenos más grande de América Latina. De esta manera, a los chilenos residentes en Brasil y viceversa, se les denomina coloquialmente como "brachilenos" como señal de aprecio y sincretismo cultural (Pieroni, 2017). 
frontera son mal vistos, mientras que paralelamente se idealizan a aquellos que proceden de Europa o Norteamérica.

Esta diferente percepción valorativa sobre los migrantes, que manifiesta la sociedad chilena, responde a la fuerte admiración que una amplia parte de dicha sociedad muestra hacia diferentes países en aspectos como la educación, la economía y los estilos de vida. En esta línea, autores como Aguayo (2011), explican que los chilenos consideran como superiores aquellos países con altos niveles culturales y educativos, como es el caso de Estados Unidos y diversos países europeos (Alemania, España, Francia, etc.). Se trata de una admiración que conlleva la idealización de ciertos aspectos físicos, como por ejemplo tener una mayor altura, ojos claros, piel blanca, etc. Se trata de aspectos ligados a culturas distantes como la europea o la norteamericana, mientras que los rasgos físicos propios de los países más cercanos (como Perú o Bolivia), tienden a ser rechazados. En definitiva, esta xenofilia discriminatoria que idealiza culturas como la europea, provoca que los migrantes españoles sean mejor percibidos, y en consecuencia, tengan mayores facilidades para superar las distintas barreras migratorias.

Pero, aunque como hemos visto los migrantes españoles tienen mayores facilidades para su inserción sociocultural en la sociedad chilena, al no existir importantes barreras como por ejemplo percibir discriminación (sino que por el contrario son considerados como una migración positiva para el país), sí experimentan algunas dificultades a la hora de integrarse en los nuevos entornos a los que acceden. Esto responde a las relevantes diferencias culturales que existen en el momento de relacionarse, construir el grupo de iguales o percibir el ocio:

Los chilenos forman su grupo de amigos de manera muy exclusiva, y lo hacen durante las etapas de la universidad y del colegio, siendo amistades que mantienen de por vida. Si tú no estuviste en esos espacios o no te moviste en tales círculos, te quedas fuera. Tiene que ver mucho con la cultura de aquí, son muy clasistas en ese sentido, entonces tienes muchos ámbitos donde te excluyen y te da la sensación de estar aislado. Cualquier círculo de amigos que trates de formar aquí, nunca llega a ser igual que el que tenías en España. (Consultor en empresa de telecomunicaciones, 34 años).

Aprovechamos el ocio de forma totalmente distinta, ellos pasan el fin de semana metidos en casa o preparando un asado, es su principal forma de pasar el tiempo libre, mientras que el español es más callejero, de moverse, de no pararse en un sitio. Eso crea una importante división y es complicado poder entablar amistad, además de que no te permiten entrar en sus círculos de amigos, te excluyen. (Ingeniero de proyectos energéticos, 35 años).

Esta dificultad a la hora de relacionarse con la población autóctona, se suma a la percepción de una progresiva pérdida de bienestar social debido a aspectos como: la mala calidad de la asistencia sanitaria, las precarias condiciones laborales, la fuerte contaminación ambiental, la existencia de un fuerte clasismo y la extrema pobreza social. Estos efectos comunes de un Estado neoliberal fundamentado en la competencia, llevan a los migrantes españoles a desarrollar una estrategia de aculturación de segregación, es decir, para defenderse ante tales dificultades, tienden a arroparse en un grupo de iguales constituido mayoritariamente por otros españoles emigrados, generando un espacio donde reproducen las pautas culturales de España, y en última instancia, debido a los frustrantes discursos en torno a la antedicha ausencia de bienestar social que perciben en Chile, terminan idealizando el retorno. Podemos observar dicha idealización de la sociedad de partida en el siguiente fragmento de entrevista: 
Los españoles aquí somos un auténtico gueto, nos juntamos entre nosotros, vamos sólo a bares españoles, si observas bien, verás que hay muchos bares de españoles donde únicamente hay españoles, y se dedican a conversar desde una perspectiva de frustración y desánimo, como si estar aquí fuera un castigo y necesitaran urgentemente volver a España. Cuando pasas mucho tiempo en este contexto, es lógico que termines retornando. (Consultor en empresa de telecomunicaciones, 34 años).

\subsection{Conflicto migratorio: entre el crecimiento profesional y la ausencia de bienestar social}

La autopercepción de estos jóvenes españoles sobre su inicio migratorio es positiva, así, tienden a remarcar del mismo aspectos como el desarrollo profesional y la estabilidad laboral. De esta manera, subrayan que el nuevo entorno de acogida les otorga la oportunidad de desarrollar una fuerte identidad profesional, contrariamente a la incertidumbre propia de las experiencias que vivían en España. Pero, esta aparentemente atractiva percepción inicial, a medida que se afianza el proyecto migratorio y los jóvenes pasan una larga etapa en Chile (en torno a los tres años de permanencia), se convierte en un importante conflicto de intereses provocado por el crecimiento profesional que les brinda el país, en contraposición a la progresiva pérdida de bienestar social que comienzan a sufrir; aspecto que podemos observar en el discurso de algunos de los jóvenes entrevistados:

En un primer momento me encontraba bien al ver que crecía en el ámbito profesional, pero con el paso del tiempo chocas con la realidad, y aprendes que no se puede asumir chile como país para asentarte y pasar el resto de tu vida, cuando ves las condiciones sociales existentes aquí es complicado. Comprendes que si por ejemplo tienes un accidente laboral o de tráfico, te va a quedar una deuda para toda la vida, que si sufres un cáncer te vas a endeudar, y si no lo superas, esa deuda pasará a tu familia. Cuando piensas en este sistema tan neoliberal y egoísta te dices a ti mismo: necesito regresar a España. Probablemente no logres un trabajo digno, pero si padeces alguna enfermedad no te vas a endeudar. Y no olvidemos el tema de la jubilación, aquí a un médico, un profesor, o un abogado, no les queda prácticamente nada de jubilación, tienen que vivir como pueden, a veces, incluso, vendiendo comida en las calles. (Profesora en escuela municipal, 26 años).

Se trata de aspectos que como vimos en el apartado anterior, están fuertemente vinculados al neoliberalismo de mercado en el que se asienta la sociedad Chilena, y que en última instancia, provocan que gran parte de los profesionales españoles emigrados en el país, opten por retornar (o re-emigrar a otro país). Así, estos jóvenes comienzan a crear en sus imaginarios sociales un "plano ideal", donde enfatizan la idea de que España está experimentando una mejora económica y laboral, y que gracias a sus experiencias profesionales desarrolladas en Chile, no tendrán muchas dificultades en encontrar un empleo:

Creo que España está comenzando a salir de la crisis, las conversaciones con mis amigos españoles y lo que leo en la prensa, me llevan a tener ese optimismo. Así que no tardaré en volver, con todo lo que he aprendido aquí espero no tener dificultades para lograr un trabajo de arquitecto en España. (Arquitecto técnico, 35 años).

Igualmente, este choque cultural producido por la socialización que estos jóvenes han tenido en un Estado de Bienestar como el español, y las experiencias desarrolladas en un Estado Neoliberal 
de mercado, genera que retornen con una mayor conciencia social ante la defensa de los servicios públicos:

Mi experiencia en Chile me hace conocer realmente el valor que tienen una sanidad y una educación públicas. Mis amigos que se han quedado en España no poseen este conocimiento, yo tengo claro que retorno para pelear, para no permitir que nos sigan quitando calidad de vida en España, para que en el futuro, España no sea igual que Chile socialmente hablando. Lo comentamos el otro día un grupo de españoles que nos volvemos: llegamos a Chile como corderos, pero volvemos a España como verdaderos leones. (Socióloga, 32 años).

Por último, otro aspecto a destacar que manifiesta la fuerte idealización del retorno por parte de estos jóvenes migrantes, es que decisiones tan significativas como la de ser padres, aunque vengan acompañadas de una estabilidad profesional y económica, el hecho de tomarlas en una sociedad como la chilena, conlleva un claro incentivo para plantearse la vuelta a España más que para asentarse definitivamente. Fundamentalmente, esto responde a no querer educar a los hijos en una sociedad en la que predomina la privatización de los servicios públicos, con el consiguiente aumento de las desigualdades sociales que ello propicia:

Ha supuesto una gran alegría tener aquí a nuestro hijo, nos va muy bien en lo económico y en lo profesional, de ahí que nos hayamos animado a tenerlo. Pero, por otro lado, es una circunstancia que nos ha llevado a decidir volver a España. No deseamos que nuestro hijo crezca en una sociedad tan injusta, tan clasista y tan desigual. Además, tendríamos que correr con los gastos de una educación privada y de mala calidad. Ya nos hemos planteado nuestra vuelta, aunque nos de pena dejar unos trabajos tan buenos y volver a la incertidumbre de la vida en España. Preferimos anteponer esta ausencia de bienestar social a nuestro crecimiento económico, una vida digna está antes que el dinero. (Profesor de Universidad, 29 años).

\section{Consideraciones finales: la inserción nostálgica experimentada por los jóvenes españoles residentes en Chile}

Como se ha constatado en la investigación aquí presentada, esta conocida como 'tercera oleada de migrantes españoles en Chile', parece estar representada principalmente por jóvenes cualificados en diversas áreas técnicas como la ingeniería, la arquitectura y la geología (como así lo muestran los datos aportados por el Departamento de Extranjería y Migración de Chile). Tratándose en una amplia mayoría de jóvenes sin cargas familiares, que han decidido emigrar para dejar atrás el entorno de precariedad laboral al que se veían destinados en España.

Estos migrantes autodenominados como "exiliados laborales", parecen seguir una inserción sociocultural que podríamos definir como nostálgica. Así, como consecuencia de la percepción de ausencia de bienestar social que sufren en Chile, provocada esencialmente por la privatización de servicios como la sanidad o la educación (cuyos costes son asumidos individualmente por los propios ciudadanos), unido a las dificultades para relacionarse con la población autóctona (debido a las diferencias culturales a la hora de entender el ocio o las relaciones de amistad), tienden a refugiarse en grupos de iguales conformados por otros migrantes españoles. De esta manera, construyen espacios donde, a través de discursos fundamentados en la frustración y el pesimismo que les genera la antedicha pérdida de bienestar, idealizan la sociedad de partida y el retorno. 
Si bien es cierto que al comienzo de sus proyectos migratorios muestran una actitud positiva, remarcando la estabilidad laboral y económica, una vez que se asientan en la sociedad chilena, comienzan a percatarse de la progresiva pérdida de bienestar y seguridad social. De la misma manera, empiezan a confrontar con unas realidades sociales con las que son difíciles convivir, como por ejemplo, la existencia de un fuerte clasismo, la elevada contaminación medioambiental y los problemas de salud que provoca, el débil sistema de jubilación, los elevados costes de la educación y la sanidad, los altos índices de malestar social, y fruto de todo esto, la grave situación de pobreza extrema que experimenta el país. Tales situaciones, difíciles de comprender para unos jóvenes socializados en un Estado de Bienestar, les llevan a construir un imaginario social, donde volver a España, se convierte en una opción prioritaria y deseable, aunque, incluso, dicha opción conlleve abandonar la estabilidad laboral y económica conseguida en el nuevo país de acogida.

Por tanto, el modelo construido por Entrena-Durán y Rodríguez-Puertas (2017), que muestra cómo los procesos de adaptación que desarrollan los jóvenes españoles migrantes, presentan un carácter versátil pudiendo desarrollar los mismos tres estrategias adaptativas: la nativofóbica, la nativofílica y la adaptación híbrida; parece no cumplirse en el caso de aquellos jóvenes españoles migrados a Chile (en este caso no asistimos a tal versatilidad, decantándose la mayor parte de los informantes entrevistados por una estrategia adaptativa, donde predomina la nostalgia por la sociedad de origen). Esto responde, como se ha explicado en líneas anteriores, a que el choque que experimentan estos jóvenes con una sociedad fundamentada en un neoliberalismo de mercado, les lleva a desarrollar mayoritariamente una estrategia de inserción marcada por una intensa subjetividad nativofílica, así, dicha subjetividad, les lleva a resguardarse de las negativas experiencias que viven (y perciben), a través de la configuración de grupos de pares conformados principalmente por otros españoles emigrados, con los que construyen contextos donde idealizan la sociedad española (y la vuelta a la misma), y, en consecuencia, reconstruyen el retorno como la opción más factible y segura. De esta manera, la aplicación de dicho modelo tridimensional en el contexto chileno, abre nuevas líneas de análisis en torno a esta nueva emigración juvenil española, donde habría que incorporar otros factores relevantes como: el bienestar social que perciben los migrantes, y la confrontación con diferentes sistemas sociales, políticos y económicos, a los existentes en origen.

\section{Agradecimientos}

El autor quiere agradecer a la Universidad Alberto Hurtado de Santiago de Chile, y especialmente, a la profesora y Directora del área de sociología, Carolina Stefoni, por la oportunidad brindada para realizar una estancia de investigación, que tuvo lugar entre los meses de marzo y junio de 2016, y que ha resultado esencial para la elaboración del presente trabajo.

Igualmente, se quiere dar las gracias al profesor y Director del Observatorio de Desigualdades de la Universidad Diego Portales, Cristian Doña, por la ayuda aportada a la hora de contextualizar la investigación aquí presentada. Y por último, y no menos importante, agradecer también el apoyo prestado a Claudia Silva Dittborn, Jefa de la Sección de Estudios del Departamento de Extranjería y Migración de Chile, que proporcionó datos fundamentales para el desarrollo del presente artículo. 


\section{Referencias bibliográficas}

- Aguayo, Claudia A. (2011). Xenofobia y xenofilia: Imaginarios sociales en materia de inmigración en las ciudades de Valparaíso y Santiago. Chile: Universidad de Concepción.

- Ardila, Erwin, y Rueda, Juan F. (2013). La saturación teórica en la teoría fundamentada: su delimitación en el análisis de trayectorias de vida de víctimas del desplazamiento forzado en Colombia. Revista colombiana de sociología, (2), 93-114.

- Béjar, Ramón C. (2005). Inversiones directas españolas en América Latina 2000-2004: situación y perspectivas. Documentos CIDOB. América Latina, (5) 1, 7-76.

- Cabezas, Marcela., Bustamante Andrés., Ballesteros Víctor y Valenzuela Felipe (2011). Estratificación Socioeconómica en Encuestas de Hogares. Chile: Instituto Nacional de Estadística.

- CIS. Centro de Investigaciones Sociológicas. (2012). Estudio n².932. Disponible en http://www.cis.es/cis/ opencm/ES/1_encuestas/estudios/ver.jsp?estudio=12564

- Córdova, Rodolfo (2015). Rutas y dinámicas migratorias entre los países de América Latina y el Caribe (ALC) y entre ALC y la Unión Europea. Ginebra: Organización Internacional para las Migraciones.

- Departamento de Extranjería y Migración de Chile (2013). https://www.extranjeria.gob.cl [consulta: 22 de enero de 2019].

- Docquier, Frédéric., Özden, Çaglar y Peri, Giovanni (2010). "The wage effects of inmigration and emigration". NBER Working Paper, 166-46, 1-46.

- Domingo, Andreu., Sabater, Abert., y Ortega, Enrique (2014). ¿Migración neohispánica? El impacto de la crisis económica en la emigración española. EMPIRIA: Revista de Metodología de Ciencias Sociales, 17 (29), 39-66.

- Entrena-Durán, Francisco y Rodríguez-Puertas, Rubén (2017). Procesos de construcción de la identidad en jóvenes universitarios españoles migrados en el extranjero. CienciaUAT, 11(2), 64-79.

- Glaser, Barney y Strauss, Anselm (1967). The Discovery of Grounded Theory: Strategies for Qualitative Research. New York: Aldine Publishing Company.

- Gonzáles-Ferrer, Amparo (2013). La nueva emigración española. Lo que sabemos y lo que no. Zoom Político, 18, 1-18.

- González, Ana M. (2014). ¿Camuflaje o transformación? Estrategia profesional de las mujeres en carreras tecnológicas altamente masculinizadas. Educar, 50(1), 187-205.

- Greene, Margarita., Rosas, José y Valenzuela, Luis (2011). Santiago. Proyecto urbano. Santiago de Chile: Ediciones ARQ.

- INE-E (2013). www.ine.es [consulta: 20 de enero de 2019].

- INE-E (2014). www.ine.es [consulta: 21 de enero de 2019].

- INE-E (2015). www.ine.es [consulta: 22 de enero de 2019].

- INE-E (2017).www.ine.es [consulta: 25 de enero de 2019].

- Instituto Nacional de Estadística de Chile (2013). www.ine.cl [consulta: 22 de enero de 2019].

- Joignant, Alfredo y Güell, Pedro (2009). El arte de clasificar a los chilenos. Enfoques sobre los modelos de estratificación en Chile. Santiago de Chile: Ediciones Universidad Diego Portales.

- Pieroni, Iuri (2017). "Brachilenos" e outros recortes migratórios: elementos significativos da imigração brasileira em Santiago do Chile. Brasil: Universidad de Brasilia.

- Real Instituto Elcano (2013). Barómetro de opinión. Trigésima segunda oleada. Disponible en http://www.realinstitutoelcano.org/wps/portal/rielcano/contenido?WCM_GLOB AL_CONTEXT=/elcano/elcano_es/barometro/ oleadabrie 32

- Rodríguez-Fariñas, María., Romero-Valiente, Juan M. y Hidalgo-Capitán, Antonio L. (2015). "Los exiliados económicos: La tercera oleada de emigración española a Chile (2008-2014)”. Revista de geografía Norte Grande, (61), $107-133$

- Rodríguez-Puertas, Rubén (2017). Características de la nueva emigración española: un análisis descriptivo de un fenómeno difícil de cuantificar. Revista de Derecho Migratorio y Extranjería, 45, 39-66.

- Sassen, Saskia (2007). Una sociología de la globalización. Buenos Aires: Katz Editores.

- Sassone, Susana M. y Yépez, Isabel (2014). Crisis global y el sistema migratorio Europa-América Latina. Revista CIDOB d'Afers Internacionals, 106-107, 13-38. 
- Standing, Guy (2013). El precariado. Barcelona: Ediciones de pasado y presente.

- Strauss, Anselm y Corbin, Juliet (1990). Basics of Qualitative Research: Grounded Theory, Procedures and Techniques. Newbury Park, Ca: Sage Publications.

- Ubilla, Rodrigo., Avaira, Andrea y Hernández, José (2015). Bitácora social II: ¿Aceptación o discriminación en Chile?. Chile: Universidad Autónoma de Chile.

- Valles, Miguel (2003). Técnicas cualitativas de investigación social. Reflexión metodológica y práctica profesional. Madrid: Editorial Síntesis.

\section{Sobre el autor}

Rubén Rodríguez Puertas

Doctor en Estudios Migratorios por la Universidad de Granada, la Universidad de Jaén y la Universidad Pablo de Olavide de Sevilla (2017), y Licenciado en Sociología por la Universidad de Granada (2010). Actualmente, es Profesor en el Departamento de Geografía, Historia y Humanidades (área de Sociología) de la Universidad de Almería, y miembro del grupo de investigación SEJ419: Sección de Sociología. Asimismo, cabe destacar su participación como evaluador de artículos científicos en la Revista Iztapalapa de la UAM (2017) y en la Revista de Estudios de las Mujeres (2018), y como Técnico de Proyectos Internacionales en la Unión Iberoamericana de Municipalistas (2014-2015). Sus principales líneas de trabajo son: globalización, migraciones internacionales, juventud y mercado de trabajo. Entre sus últimas publicaciones se encuentran: <<Marea Granate: el empoderamiento de los migrantes españoles frente al vacío estatal $>>$ (2018), <<Características de la nueva emigración española: una análisis descriptivo de un fenómeno difícil de cuantificar $>>(2017)$ y $<<$ Procesos de construcción de la identidad en jóvenes universitarios españoles migrados al extranjero $>>(2017)$. 